\title{
A NOTE ON THE AUTOMOBILE ACCIDENT COMPENSATION PLAN
}

The workmen's compensation law passed from the stage of a social experiment to that of an established institution at the very time that the automobile accident began to present many of the same social problems out of which had come the demand for the compensation plan of distributing the economic losses incident to industrial injuries. It is not surprising, then, that there should soon have arisen a similar demand for the treatment of the automobile accident claim in a manner analogous to that embodied in workmen's compensation legislation.

Proposals to this end began to appear as early as I9I9. ${ }^{1}$ A few years later a vigorous impetus to professional and public interest in the subject was given by Judge Robert S. Marx of Cincinnati who devised and sponsored a plan to abolish fault as a basis of liability, to make liability insurance compulsory, and to provide an administrative body to pass upon claims for compensation. But the most notable step in exploring the feasibility and desirability of the compensation plan came with the organization in 1928, under the auspices of the Columbia University Council for Research in the Social Sciences, of a Committee to Study Compensation for Automobile Accidents. A research grant was obtained, and a staff, under the direction of Shippen Lewis, Esq., of the Philadelphia Bar, a contributor to this symposium, began the study of "the law and the facts with respect to compensation for motor vehicle accidents, with the object of presenting an unbiased statement of . . . findings, and suggestions for the solution of the problems involved." The study "included the investigation of 8,849 cases of personal injury and death caused by motor accidents, the assembling of data furnished by public officials and insurance companies, the examination of statutes and judicial decisions and the analysis of pamphlets and articles dealing with the problem."

Out of this study, came the suggestion of an automobile compensation plan which has served as the focus of much of the discussion of the subject since the publication of the Committee's 300-page report in 1932. The purpose of this note is to present the outline of that plan as developed in the Committee's report. ${ }^{2}$ For a discussion

${ }^{2}$ For references to the principal articles on this subject, see Braun, The Financial Responsibility Law, supra, p. 000; Lewis, The Merits of the Automobile Accident Compensation Plan, infra, passim; Sherman, Grounds for Opposing the Automobile Accident Compensation Plan, infra, passim.

"Report of the Commitiee to Study Compensation for Automobile Accidents to the Columbia Committee for Research in the Social Sciences (1932) 138-r43. (The editor acknowledges with appreciation the Council's permission to quote the passages from this Report set forth below.) The director of the study, Mr. Lewis, also drafted "certain substantive parts of a compensation act" which was not, however, adopted by the Committec. For its text, see id., 236-245. 
of the merits and demerits of the proposal, the reader is referred to the succeeding articles by Mr. Lewis and by Mr. P. Tecumseh Sherman of the New York Bar, who has acted as consultant to casualty insurance companies with respect to this legislation. A few passages which did not seem essential to the purposes of this paper have been omitted from the Committee's statement.

D. F. C.

\section{OUTLINE OF AN ASSUMED PLAN}

a. Liability to Pay Compensation: The general purpose of the compensation plan is to impose on the owners of motor vehicles a limited liability, without regard to fault, for personal injury or death caused by the operation of their motor vehicles. The liability to pay rests primarily on the owner of the motor vehicle and the plan provides security for this liability by requiring every registered motor vehicle to be covered by compensation insurance.

The owner of any motor vehicle which causes injury or death must pay compensation if the motor vehicle at the time of the accident was driven by him or by another with his consent. This gives a remedy in every case except those in which the motor vehicle has been operated without the owner's consent or cannot be identified. If the motor vehicle is registered in another state, the owner's liability is the same, although there is no practical way of enforcing the insurance requirement. Hence, if the owner of an out-of-state car carries insurance against compensation liability, the injured person will be protected, while if he carries no such insurance, the injured person will stand exactly as he stands now with an uninsured defendant, except that he will have the right to defined benefits and will not have to prove negligence.

b. Cause the Basis of Liability: When can a motor vehicle be said to cause injury or death? This question is also presented in applying the law of negligence. The Committee suggests that a compensation law should use the word "cause" allowing the administrative board and the courts to apply accepted legal principles in the process of interpretation. It would of course be possible to limit the liability of an owner to cases in which his motor vehicle caused the injury by collision, thus omitting such cases as those in which a motorist causes an accident by his glaring headlights or by forcing another off the highway.

c. INCIDENCE OF LIABILITY: In cases involving simply a pedestrian struck by a motor vehicle the owner of the motor vehicle must of course pay compensation. But where two motor vehicles collide, the problem is more complex. Here the Committee believes that it will be best to require each owner to compensate the occupants of his own motor vehicle, except the owner himself, who will look to the owner of the other motor vehicle for compensation. ...

In the occasional case where more than two motor vehicles cause the accident, any owner injured will be entitled to claim against the other owners jointly; otherwise the situation will be the same as where only two motor vehicles cause the accident.

A pedestrian or other person outside of a motor vehicle whose injury is caused by more than one motor vehicle will be entitled to recover compensation from all the motor vehicle owners jointly.

d. Subrogatron: If the accident has been caused by the negligence of someone not concerned in it as the occupant or owner of a motor vehicle or as a person injured, the owner or insurance carrier who has been obliged to pay compensation will be entitled to recoup by an action of damages against the negligent person. . . . 
e. Who Recerves Compensatron: Compensation is to be paid in respect of any injury or death caused by the operation of a motor vehicle, unless the person injured or killed wilfully intended to cause injury to himself or to another. The Committee believes also that injuries to owners and operators of motor vehicles should be excluded, unless they are caused by another motor vehicle. . . .

f. Scale of Benefits: The Committee has drafted the following schedule of benefits based on the workmen's compensation laws of New York and of Massachusetts.

(x) Medical Benefits: The cost of medical care is paid in all cases regardless of the duration of disability (this follows the New York law, in Massachusetts such cost is paid only during the first two weeks of disability and in unusual cases).

(2) Waiting Period: No compensation is paid for the first week of disability.

(3) Weekly Wages: Compensation is based on weekly wages. For employed persons these are calculated as under the workmen's compensation law. For business and professional men, profits take the place of wages in the calculation. For persons temporarily unemployed, wages are calculated by reference to the last period of steady employment. For housewives, wages are assumed to be those paid for similar work at the time and place of their occupation. For permanently unemployed persons, for unemployed minors of nineteen and under, and for students of over nineteen, the minimum wage of $\$ 8.00$ is assumed. (New York, $\$ 8.00$; Massachusetts, \$9.00.)

(4) Permanent Total Disability: The injured person received two-thirds of his weekly wages during the continuance of the disability.

(5) Temporary Total Disability: The injured person receives two-thirds of his weekly wages during the continuance of his disability.

(6) Permanent Partial Disability: As in workmen's compensation, the plan includes a schedule listing various types of dismemberments or loss of use of members. In respect of each an injured person is entitled to receive two-thirds of his average weekly wages for a specified number of weeks, adjusted roughly to the seriousness of the case; if the injury is not covered by the schedule he receives two-thirds of the difference between his wages before and after the accident. In cases of unemployed minors and in other cases where it shall be equitable, the compensation board may estimate the wages which the injured person would have received from time to time.

(7) Temporary Partial Disability: During the continuance of temporary partial disability the injured person receives two-thirds of the difference between his wages before and after the accident.

(8) Disfigurement: For serious facial or head disfigurement or other disfigurement impairing the earning power of the injured person, he receives a proper and equitable amount, not to exceed $\$ 3,500$ (New York only).

(9) Death: Compensation in death cases is as follows:

(a) Funeral Expenses: Funeral expenses are paid in all cases, not exceeding \$200 (New York, \$200; Massachusetts, \$150).

(b) Earners with dependents: The dependents receive compensation as provided by the workmen's compensation law of the state. This includes earners temporarily unemployed.

(c) Housewives: Members of the family of the deceased living in her household receive a minimum of $\$ 500$ and a maximum of $\$ 1,500$.

(d) Children: For unemployed children of nineteen and under, the parents or the surviving parent receive a minimum of $\$ 500$ and a maximum of $\$ 2,500$.

(e) Students: For unemployed students over nineteen, compensation is paid to the wife and children or to supporting parents, as in the case of employed persons, but with an assumed wage of $\$$ ro a week. 
(f) Earners without dependents: No compensation is paid with respect to earners without dependents, except the amount provided for the funeral.

(g) Unemployed persons: No compensation is paid with respect to permanently unemployed persons, except the amount provided for the funeral.

(ro) Maximum and Minimum: The maximum and the minimum compensations payable for different kinds of disability are in addition to those already stated as follows:

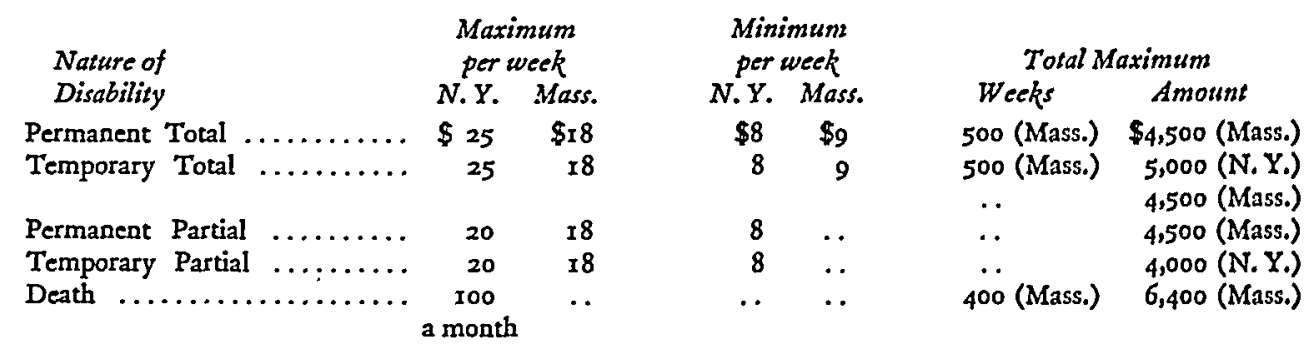

g. Insurance: No motor vehicle can be registered unless the owner presents a certificate showing that he has procured insurance against liability to pay compensation. As to whether insurance should be carried with private companies, with an exclusive state fund, or with private companies and a competitive state fund, each state would presumably follow its practice with respect to workmen's compensation.

h. Exclusiveness of Remedy: The compensation provided by the plan is in lieu of all other, compensation or damages for personal injury or death caused by the operation of a motor vehicle, except as to cases expressly excluded from the operation of the act. An example of a case so excluded is that of an operator who strikes a train; he would still have his action against the railroad company based on the law of negligence. . . .

i. Administration: The compensation plan is to be administered by a special board created for that purpose, with the assistance of such referees and clerks as may be required. Procedure will follow that now in effect under workmen's compensation.

j. Reports: Owners and operators involved in accidents will be required to report within a prescribed time to the commissioner of motor vehicles, and persons injured will be required within a prescribed time to give notice to the compensaton board and to the insured motorist, stating the extent of injury and the name and address of the attending physician. 